\title{
Single bolus intravenous regadenoson injection versus central venous infusion of adenosine for maximum coronary hyperaemia in fractional flow reserve measurement
}

\author{
Citation for published version (APA): \\ van Nunen, L., Lenders, G. D., Schampaert, S., van 't Veer, M., Wijnbergen, I. F., Brueren, B. R. G., Tonino, W. \\ A. L., \& Pijls, N. (2015). Single bolus intravenous regadenoson injection versus central venous infusion of \\ adenosine for maximum coronary hyperaemia in fractional flow reserve measurement. Eurolntervention, 11(8), \\ 905-913. https://doi.org/10.4244/EIJY14M08_10
}

\section{Document license: \\ TAVERNE}

DOI:

10.4244/EIJY14M08_10

Document status and date:

Published: 01/12/2015

\section{Document Version:}

Publisher's PDF, also known as Version of Record (includes final page, issue and volume numbers)

\section{Please check the document version of this publication:}

- A submitted manuscript is the version of the article upon submission and before peer-review. There can be important differences between the submitted version and the official published version of record. People interested in the research are advised to contact the author for the final version of the publication, or visit the DOI to the publisher's website.

- The final author version and the galley proof are versions of the publication after peer review.

- The final published version features the final layout of the paper including the volume, issue and page numbers.

Link to publication

\footnotetext{
General rights

- You may freely distribute the URL identifying the publication in the public portal. follow below link for the End User Agreement:

www.tue.nl/taverne

\section{Take down policy}

If you believe that this document breaches copyright please contact us at:

openaccess@tue.nl

providing details and we will investigate your claim.
}

Copyright and moral rights for the publications made accessible in the public portal are retained by the authors and/or other copyright owners and it is a condition of accessing publications that users recognise and abide by the legal requirements associated with these rights.

- Users may download and print one copy of any publication from the public portal for the purpose of private study or research.

- You may not further distribute the material or use it for any profit-making activity or commercial gain

If the publication is distributed under the terms of Article $25 \mathrm{fa}$ of the Dutch Copyright Act, indicated by the "Taverne" license above, please 


\title{
Single bolus intravenous regadenoson injection versus central venous infusion of adenosine for maximum coronary hyperaemia in fractional flow reserve measurement
}

Eurolntervention 2015;11:905-913 published online ahead of print August 2014. DOI: 10.4244/EIJY14M08_10

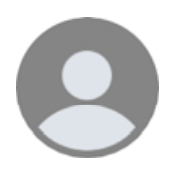

Lokien X. van Nunen, MD; Guy D. Lenders, MD; Stéphanie Schampaert, MSc; Marcel van 't Veer, PhD; Inge Wijnbergen, MD; Guus R.G. Brueren, MD, PhD; Pim A.L. Tonino, MD, PhD; Nico H.J. Pijls*, MD, PhD

Department of Cardiology, Catharina Hospital Eindhoven, Eindhoven, The Netherlands

\begin{abstract}
Aims: The aim of this study was to compare the hyperaemic effect of a single bolus regadenoson injection to a central venous adenosine infusion for inducing hyperaemia in the measurement of fractional flow reserve (FFR).

Methods and results: One hundred patients scheduled for FFR measurement were enrolled. FFR was first measured by IV adenosine ( $140 \mu \mathrm{g} / \mathrm{kg} / \mathrm{min}$ ), thereafter by IV bolus regadenoson injection ( $400 \mu \mathrm{g})$, followed by another measurement by IV adenosine and bolus injection of regadenoson. The regadenoson injections were randomised to central or peripheral intravenous. Hyperaemic response and duration of steady state maximum hyperaemia were studied, central versus peripheral venous regadenoson injections were compared, and safety and reproducibility of repeated injections were investigated. Mean age was $66 \pm 8$ years, $75 \%$ of the patients were male. The target stenosis was located in the LM, LAD, LCX, and RCA in 7\%, 54\%, 20\% and $19 \%$, respectively. There was no difference in FFR measured by adenosine or by regadenoson ( $\triangle F F R=0.00 \pm 0.01, r=0.994, p<0.001$ ). Duration of maximum hyperaemia after regadenoson was variable (10-600 s). No serious side effects of either drug were observed.
\end{abstract}

Conclusions: Maximum coronary hyperaemia can be achieved easily, rapidly, and safely by one single intravenous bolus of regadenoson administered either centrally or peripherally. Repeated regadenoson injections are safe. The hyperaemic plateau is variable. Clinical Trial Registration:

http://clinicaltrials.gov/ct2/show/study/NCT01809743?term=NCT01809743\&rank=1 (ClinicalTrials.gov Identifier: NCT01809743)

\section{Introduction}

For correct decision making with respect to revascularisation in the catheterisation laboratory and performing coronary interventions, induction of maximum coronary and myocardial hyperaemia is often indispensable. Fractional flow reserve (FFR), defined as the ratio of maximal blood flow in a stenotic artery to maximal blood flow if the same artery were completely normal, is the current standard to assess if a particular stenosis is functionally significant, i.e., capable of inducing myocardial ischaemial-3.
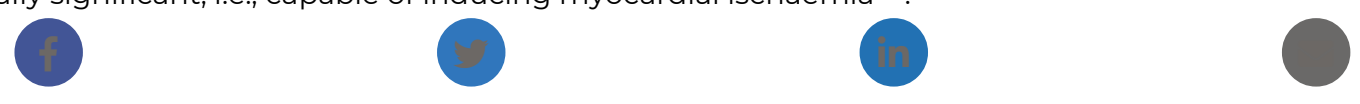
In most studies validating FFR, a central venous infusion of adenosine $(140 \mu \mathrm{g} / \mathrm{kg} / \mathrm{min})$ was used to create

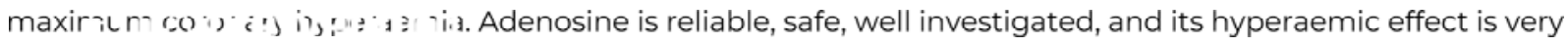
reproducible 4,5 . Side effects include innocent chest discomfort, an increase in heart rate of approximately $10 \%$ and a decrease in blood pressure of approximately 10\%, and rarely transient AV block ${ }^{4}$. Very rarely, bronchospasm might occur, which is why adenosine is generally avoided in severe asthma patients.

In many countries, production of standard infusion bags of adenosine for intravenous use (200 $\mathrm{mg}$ in $100 \mathrm{ml}$ ) is cheap and hospital-pharmacy-based. In others, the preparation of adenosine is not trivial, the price is high and the preference for central venous infusion, with the need for a femoral sheath, may be a barrier to its use. Consequently, some physicians avoid central venous administration of adenosine. In an attempt to simplify coronary physiologic measurements, some physicians have opted to abandon maximum coronary hyperaemia and to rely upon resting indices like the distal to proximal pressure ratio at rest (Pd/Parest) or the instantaneous wave-free ratio (iFR) 6 , both equally performing but decreasing diagnostic accuracy5,7,8. Therefore, endeavours to find other, easy-to-use pharmacologic stimuli to replace central venous adenosine administration are indisputable.

Regadenoson is a relatively new, A2A-receptor selective, non-weight-based hyperaemic stimulus known for its rapid onset and simple method of administration, approved for use in myocardial perfusion imaging 9 . Several non-randomised studies have been performed to investigate regadenoson for FFR measurement10-12.

The present randomised study in 100 patients was performed with the following aims: 1) to investigate if the coronary hyperaemia induced by a single bolus regadenoson $(400 \mu \mathrm{g})$ is equal to hyperaemia induced by central venous adenosine infusion ( $140 \mu \mathrm{g} / \mathrm{kg} / \mathrm{min}) ; 2$ ) to determine the time intervals to onset of maximum hyperaemia and the duration of steady-state hyperaemia if present; 3) to compare central venous versus peripheral venous administration of regadenoson; and 4) to investigate any potential side effects as well as safety and reproducibility of repeated regadenoson injections.

\section{Methods}

\section{PATIENT SELECTION}

The study was approved by the institutional review board of the Catharina Hospital Eindhoven and is registered at the National Institutes of Health Clinical Trials website (NCT01809743). All patients provided written informed consent. One hundred patients between the ages of 18 and 80 years scheduled for invasive measurement of FFR for diagnostic or interventional purposes were included. All coronary artery lesions under investigation were located in the proximal or mid segment of a coronary artery with a reference diameter of at least $2.0 \mathrm{~mm}$.

Exclusion criteria were severe aortic valve stenosis, known conduction disturbances (second- or third-degree AV block), acute myocardial infarction ( $\mathrm{CK}>1,000 \mathrm{U} / \mathrm{L}$ less than five days ago), bradycardia (less than 50 beats/min), severe hypotension, extremely tortuous or calcified coronary vessels precluding FFR measurement, inability to perform catheterisation by femoral approach, history of severe asthma, pregnancy and/or inability to provide informed consent.

Because of its interaction with adenosine-mediated effects, the use of dipyridamol in the past 48 hours or the use of methylxanthines in the past 12 hours was each considered an exclusion criterion.

\section{RANDOMISATION}

Patients were randomised with respect to the sequence of regadenoson administration. According to the investigational protocol (Figure 1), FFR was first measured by central intravenous infusion of adenosine (140 $\mu \mathrm{g} / \mathrm{kg} / \mathrm{min}$ ), thereafter by intravenous bolus injection of regadenoson ( $400 \mu \mathrm{g}$ ), followed by a repetitive measurement by central intravenous infusion of adenosine and a second bolus injection of regadenoson. Regadenoson administration was randomised to central-central, central-peripheral, peripheral-central, and peripheral-peripheral, in a 1:1:1:1 ratio.
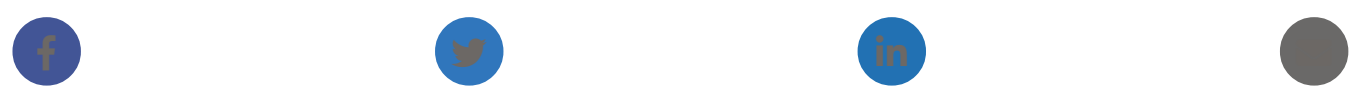


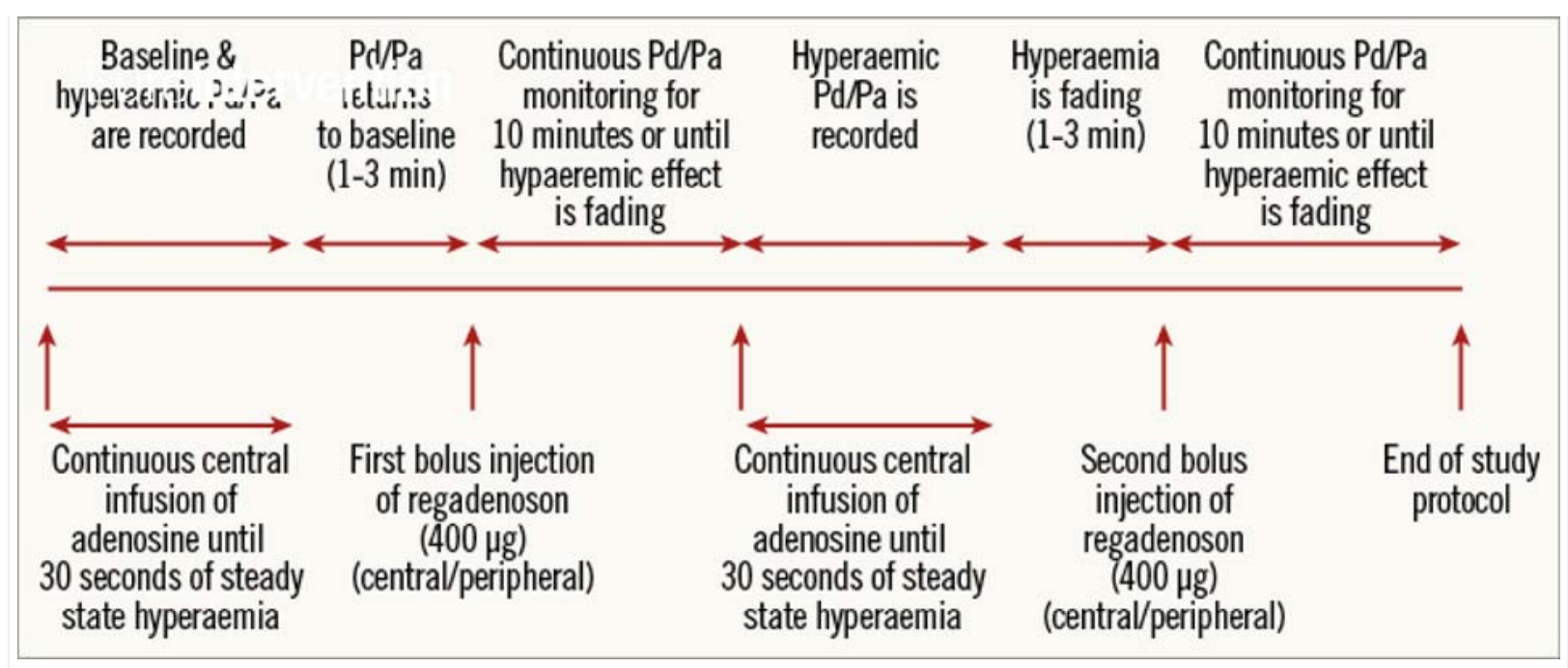

Figure 1. Measurement protocol. Measurement protocol for the different hyperaemic stimuli. True baseline $\mathrm{Pd} / \mathrm{Pa}$, as at the start of the experiment, is not achieved again in most patients during the study after the first bolus injection of regadenoson.

\section{CATHETERISATION PROTOCOL}

All patients underwent cardiac catheterisation and coronary angiography by the femoral approach using a $6 \mathrm{Fr}$ sheath in one of the femoral arteries. In all patients, a $5 \mathrm{Fr}$ femoral venous sheath was introduced and a peripheral infusion (18 gauge) was placed in the antebrachial vein or a vein located on the distal part of the forearm. An adequate guiding catheter was introduced and advanced into the coronary artery of interest and control angiograms were made in the standard manner. In each patient, only one coronary artery was selected for study purposes. Next, the pressure guidewire (PW Certus ${ }^{\mathrm{TM}}$; St. Jude Medical, St. Paul, MN, USA) Was advanced and equalised with the pressure sensor at the tip of the guiding catheter, according to state-of-theart coronary pressure measurement. Hereafter, the pressure wire was advanced into the coronary artery sufficiently distal to the study lesion, and was maintained in that position during the remaining part of the study. Distal coronary pressure (Pd) and aortic pressure ( $\mathrm{Pa})$ were measured simultaneously and recorded.

Central venous infusion of adenosine was started at a rate of $140 \mu \mathrm{g} / \mathrm{kg} / \mathrm{min}$ (Figure 1). After steady state maximum hyperaemia had been achieved and maintained for at least 30 seconds, adenosine infusion was stopped. FFR was measured as the lowest value of Pd/Pa achieved during steady state maximum hyperaemia.

As soon as haemodynamic conditions returned to baseline, the first single bolus injection of regadenoson of 400 $\mu \mathrm{g}$ (Rapidscan Pharma Solutions, London, UK) was administered, either centrally or peripherally according to the randomisation protocol, followed by a $10 \mathrm{cc}$ flush of saline. The time to onset of hyperaemia, haemodynamic conditions and duration of steady state hyperaemia were recorded. Again, FFR was measured as the lowest value of $\mathrm{Pd} / \mathrm{Pa}$ achieved during steady state hyperaemia. The duration of steady state hyperaemia was defined as the period of time from the nadir of $\mathrm{Pd} / \mathrm{Pa}$ until $\mathrm{Pd} / \mathrm{Pa}$ increased to more than 0.02 above its lowest value. Recording was continued until the hyperaemic effect had faded by at least $50 \%$, with a minimum of two and a maximum of 10 minutes. Thereafter, the second central venous infusion of adenosine was started and again maximum coronary hyperaemia was recorded for at least 30 seconds.

Finally, the second single bolus of regadenoson was administered, either centrally or peripherally according to the randomisation protocol, and its hyperaemic effect was studied again. If the maximum hyperaemic effect of the first bolus injection of regadenoson lasted longer than 10 minutes, the second bolus injection was withheld.

At the end of the measuring sequence, the pressure wire was pulled back to the tip of the guiding catheter to verify (absence of) drift in the pressure wire. If an intervention was indicated based upon the FFR measurement with adenosine (FFR value $\leq 0.80$ ), it was performed subsequently.

\section{SAFETY AND SIDE EFFECTS}

Systolic and diastolic blood pressure and heart rate were monitored continuously and differences between baseline and maximum hyperaemia with the different stimuli were recorded. Potential side effects including chest pain prtness of breath, headac ausea or any other side e affecting the patient we sessed 
and scored on a patient's discomfort scale, ranging from 1 to 10, with 1 being very little discomfort and 10 being

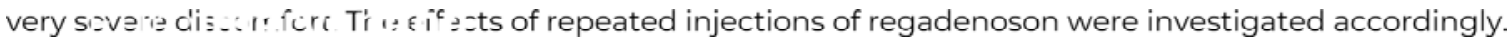

\section{STATISTICAL ANALYSIS}

Because the standard deviation of repeated FFR measurements in previous studies was $\leq 0.025,13$, we postulated that a difference of $>0.02$ in minimal $\mathrm{Pd} / \mathrm{Pa}$ would reject equivalence of regadenoson to adenosine for induction of maximum hyperaemia. To measure agreement between the two methods of measurement, a Bland-Altman plot was used besides a linear regression with Pearson's correlation coefficient and a two-tailed test for significance 14 . A sample size of 100 patients was deemed sufficient to keep standard errors of the $95 \%$ limits of agreement small as recommended by Bland14.

Data are presented as mean \pm SD. The Student's paired t-test was used to compare haemodynamic parameters from baseline to maximal hyperaemia and to compare mean overall change in haemodynamic status.

To compare the two hyperaemic stimuli, the means of both FFR values measured by the same hyperaemic stimulus were compared. Peripheral venous bolus injections of regadenoson were compared to central venous adenosine infusion as well as central venous bolus injections to central venous adenosine infusion. To test the reproducibility of maximum coronary hyperaemia induced by regadenoson and compare different methods of administration (i.e., central versus peripheral), the first and second FFR values measured with regadenoson were compared. Reproducibility of maximum coronary hyperaemia by central venous adenosine infusion was also investigated. Results were considered statistically significant at $\mathrm{p}<0.05$. Statistical analysis was performed with SPSS software version 19 (IBM Corp., Armonk, NY, USA).

\section{Results}

\section{BASELINE CHARACTERISTICS}

Baseline characteristics are presented in Table 1. In the patient population $75 \%$ were male, the mean age was $66 \pm 8$ years, mean height was $172 \pm 9 \mathrm{~cm}$ and mean body weight was $79 \pm 14 \mathrm{~kg}$. Almost all patients had multiple risk factors for coronary atherosclerosis, and $21 \%$ had diabetes mellitus. In total, $43 \%$ of the patients had undergone a previous percutaneous coronary intervention and $36 \%$ had a previous myocardial infarction. The study lesion was located in the LM, LAD, LCX, and RCA in 7\%, 54\%, 20\% and 19\%, respectively. The mean reference diameter was $3.2 \pm 0.6 \mathrm{~mm}$. The severity of coronary artery disease was well balanced within the patient population: single-vessel disease in 33\% of the population, two-vessel disease in 43\%, and three-vessel disease in $24 \%$ of the population. Visual stenosis severity varied from $30 \%$ to $>90 \%$ (Figure 2).
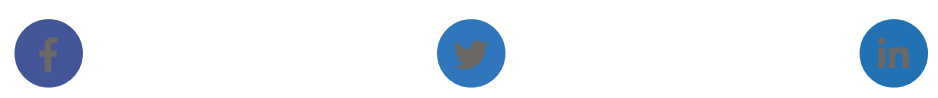
lasie :. Luseline and procedural characteristics of the study population $(\mathrm{N}=100)$.

\begin{tabular}{|c|c|c|}
\hline \multicolumn{3}{|c|}{ Baseline characteristics } \\
\hline \multicolumn{2}{|l|}{ Age (yrs) } & $66 \pm 8$ \\
\hline \multicolumn{2}{|l|}{ Male/female } & $75 / 25$ \\
\hline \multicolumn{2}{|l|}{ Length $(\mathrm{cm})$} & $172 \pm 9$ \\
\hline \multicolumn{2}{|l|}{ Weight (kg) } & $79 \pm 14$ \\
\hline \multicolumn{3}{|c|}{ Clinical characteristics } \\
\hline \multicolumn{2}{|l|}{ Hypertension } & 54 \\
\hline \multicolumn{2}{|c|}{ Hypercholesterolaemia } & 36 \\
\hline \multicolumn{2}{|c|}{ Diabetes mellitus } & 21 \\
\hline \multicolumn{2}{|c|}{ Active smoking } & 20 \\
\hline \multicolumn{2}{|c|}{ Family history of premature $C A D$} & 33 \\
\hline \multicolumn{2}{|l|}{ Previous PCI } & 43 \\
\hline \multicolumn{2}{|l|}{ Previous MI } & 36 \\
\hline \multicolumn{3}{|c|}{ Angiographic variables } \\
\hline \multicolumn{2}{|c|}{ Diagnostic/interventional procedure } & $48 / 52$ \\
\hline \multirow{3}{*}{$\begin{array}{l}\text { Severity of } \\
\text { CAD }\end{array}$} & - single-vessel & 33 \\
\hline & - 2-vessel & 43 \\
\hline & - 3-vessel & 24 \\
\hline \multirow[t]{4}{*}{ Target vessel } & - Left main & 7 \\
\hline & - Left anterior descending & 54 \\
\hline & - Left circumflex & 20 \\
\hline & - Right coronary artery & 19 \\
\hline \multicolumn{2}{|c|}{ Vessel diameter } & $3.2 \pm 0.6$ \\
\hline \multirow{4}{*}{$\begin{array}{l}\text { Stenosis } \\
\text { percentage }\end{array}$} & $-30-50 \%$ & 35 \\
\hline & $-50-70 \%$ & 38 \\
\hline & $-70-90 \%$ & 20 \\
\hline & - >90\% & 6 \\
\hline
\end{tabular}

Values are mean \pm SD or \%. CAD: coronary artery disease; MI: myocardial infarction; $\mathrm{PCl}$ : percutaneous coronary intervention 


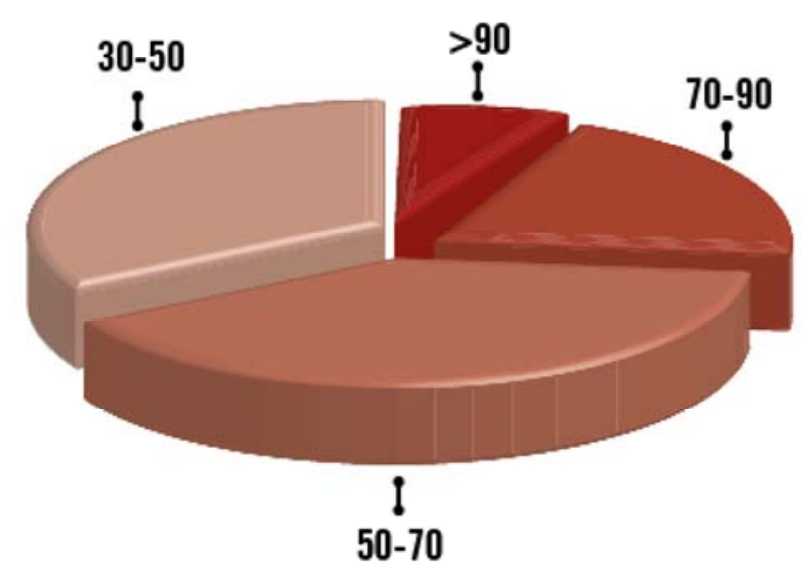

Figure 2. Visual stenosis percentage of the study lesion. Visual stenosis severity of the study lesion was 30-50\%, 50-70\%, 70-90\% and $>90 \%$ in $35 \%, 38 \%, 20 \%$ and $6 \%$, respectively.

\section{PROCEDURAL CHARACTERISTICS AND OUTCOME}

The study protocol was successfully performed in all patients without any complication. It was possible to advance a pressure guidewire to the desired location of interest in all patients. Adenosine was administered twice in all patients, and regadenoson was administered twice in 88 patients. In 12 patients, only one injection of regadenoson was administered because the maximum hyperaemic effect of regadenoson persisted beyond ten minutes.

In one patient, FFR after the first injection of regadenoson was excluded for further analysis because of drift of the pressure wire. This also happened in one patient after central venous adenosine infusion.

The average FFR value in the study population was $0.75 \pm 0.10$ (range 0.41-0.96), both with central venous infusion of adenosine as well as with bolus injections of regadenoson.

FFR was $\leq 0.80$ in 64 coronary arteries under investigation. Of the 64 haemodynamically significant lesions, 52 lesions (81\%) underwent revascularisation with $\mathrm{PCI}(55 \%)$ or CABG (27\%). Twelve lesions were treated medically due to very diffuse spatial distribution of atherosclerosis, not suitable for mechanical revascularisation. All coronary arteries investigated with an FFR $>0.80$ were treated medically.

\section{COMPARISON OF HYPERAEMIA AFTER THE DIFFERENT STIMULI}

FFR measured after central venous adenosine infusion was equal to FFR measured by either peripheral or central venous injection of regadenoson in all patients with an average difference of $0.00 \pm 0.01$ and an absolute difference of less than 0.02 in 97/100 patients ( $r=0.994, p=<0.001$ ) (Figure 3). Also, no difference was observed in FFR when comparing only central or only peripheral bolus injections of regadenoson with central venous infusion of adenosine. In not a single (0) patient was classification with respect to ischaemia with regadenoson different from classification with adenosine. 

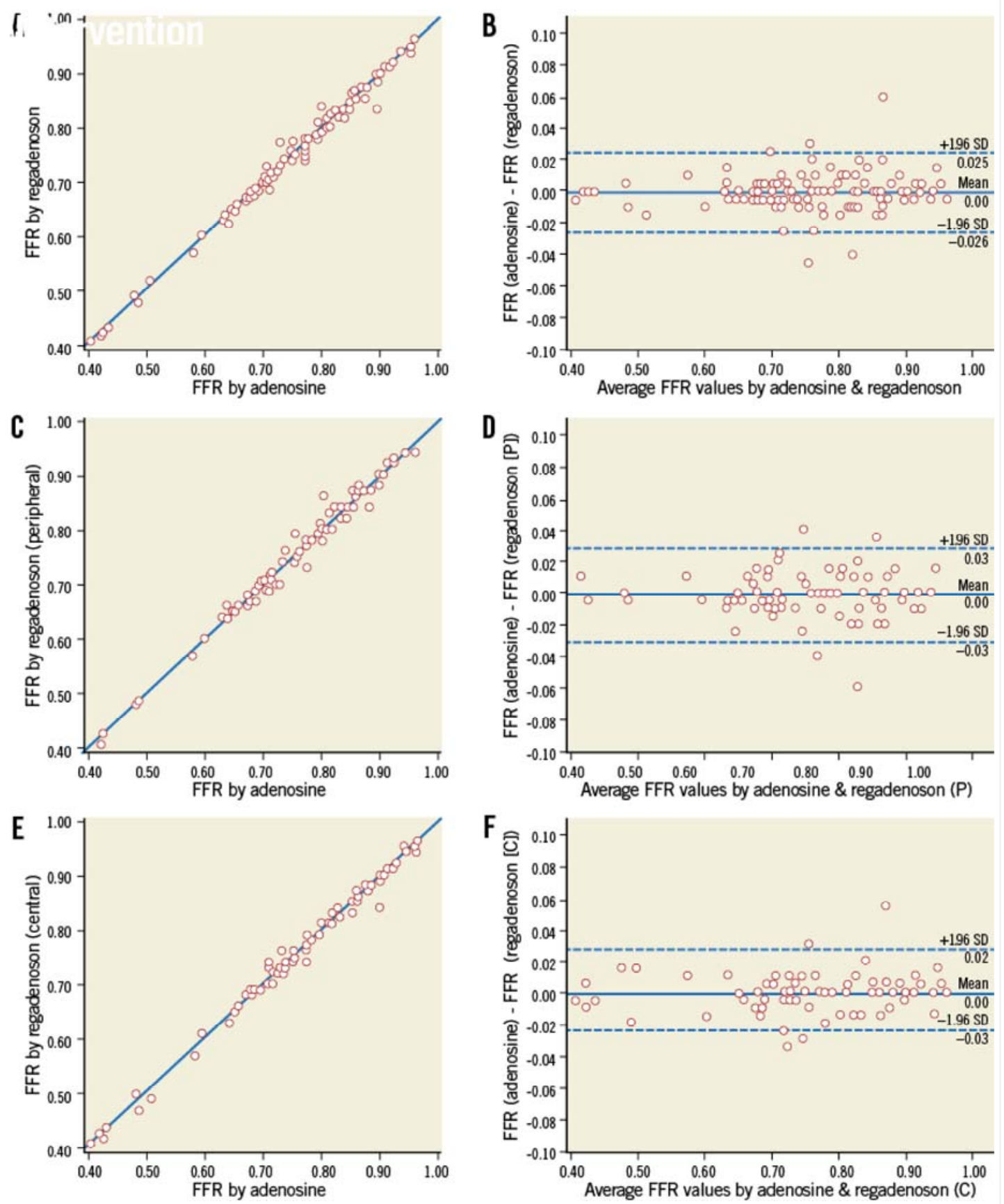

Figure 3. Linear regression analysis and Bland-Altman agreement. Relation between FFR measurement during central venous infusion of adenosine and single intravenous bolus of regadenoson in all patients ( $N=100, r=0.994, p<0.001)$ (A); in patients with at least one peripheral injection of regadenoson $(\mathrm{N}=73, \mathrm{r}=0.991, \mathrm{p}<0.001)(\mathrm{C})$; and patients with at least one central injection of regadenoson $(\mathrm{N}=72$, $r=0.995, p<0.001)(E)$, and the corresponding Bland-Altman plots (B, $D$ and $F)$.

The reproducibility of regadenoson was excellent as well, with a difference of $0.01 \pm 0.02$ between the first and the second administration, irrespective of the manner of administration ( $r=0.990, p<0.001$ ) (Figure 4A). In those patients receiving one peripherally and one centrally administered bolus injection of regadenoson, the hyperaemic effect and associated haemodynamic effects were identical. 

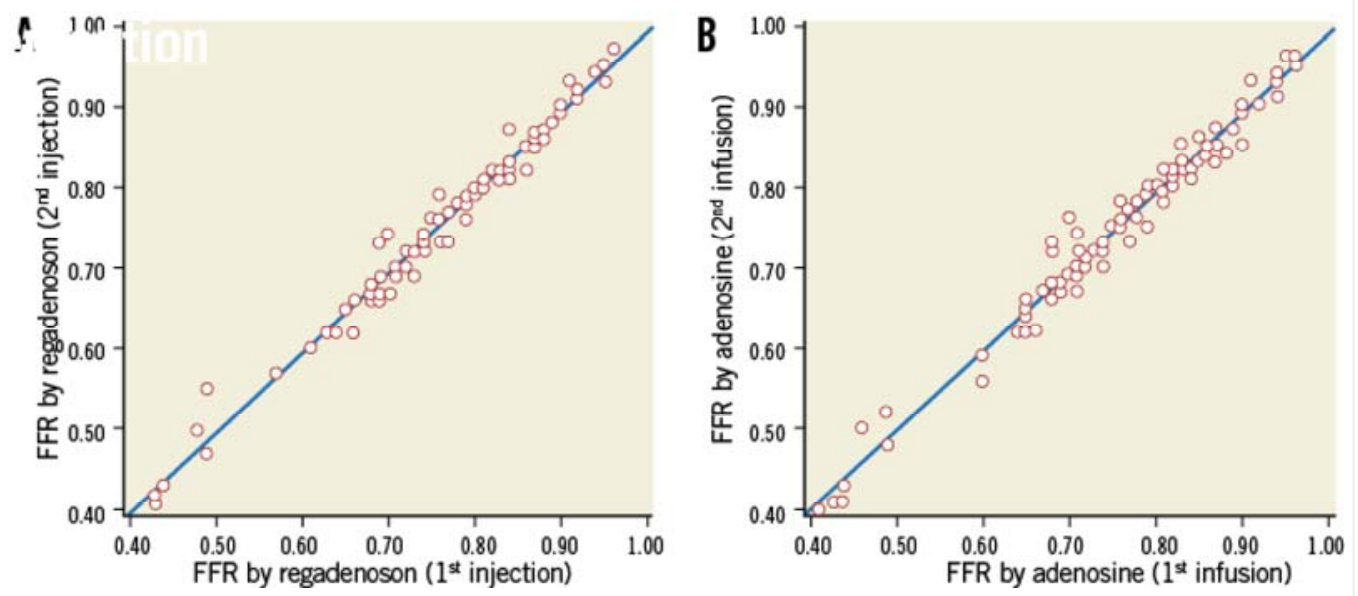

Figure 4. Reproducibility of FFR measurement by regadenoson and adenosine. Reproducibility of FFR measurement with single
intravenous bolus injections of regadenoson $(N=87, \triangle F F R=0.01 \pm 0.02, r=0.990, p<0.001)$ (A). Reproducibility of FFR measurement with
central venous adenosine infusion ( $N=99, \triangle F F R=0.01 \pm 0.02, r=0.987, p<0.001)$ (B).

Finally, as expected, coronary hyperaemia induced by central venous adenosine infusion was very reproducible as well, with a difference of $0.01 \pm 0.02(r=0.987, p=0.001)$ (Figure 4B).

\section{ONSET OF MAXIMUM HYPERAEMIA AND DURATION OF THE HYPERAEMIC PLATEAU}

The onset of hyperaemia after central venous administration of adenosine has been well described before and varies between 30 and 90 seconds. This was also the case in all patients in this study. Steady state hyperaemia could be maintained during infusion in all patients, with, in a few patients only, some small periodic fluctuations which have been described before and are attributable to rapid metabolisation of adenosine in combination with breathing or Valsalva manoeuvres.

The onset of maximum hyperaemia after central venous injection of regadenoson was $22 \pm 9$ sec, and for peripheral injection this was $30 \pm 13 \mathrm{sec}$. The duration of the hyperaemic plateau for regadenoson was variable and lasted between 10 seconds and more than 10 minutes (Figure 5). In 90\% of the patients, the plateau lasted at least 19 seconds and in 75\% it lasted at least 58 seconds. The mean duration of the hyperaemic plateau was 163 seconds.

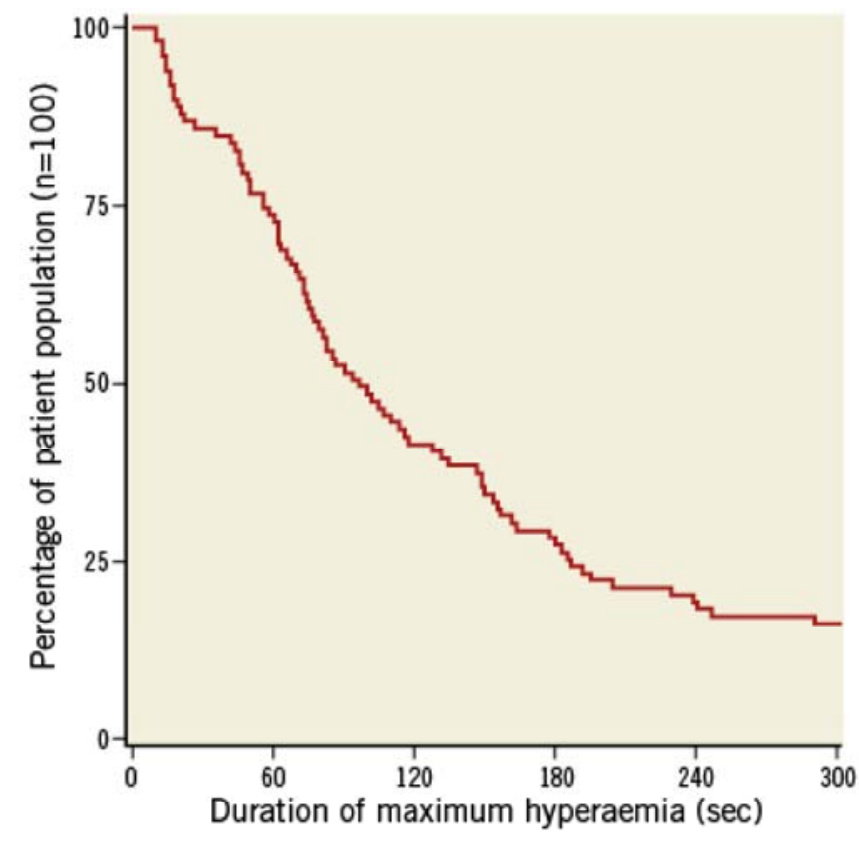


Figure 5. Duration of steady state maximum hyperaemia induced by regadenoson. Distribution of duration of the length of steady state

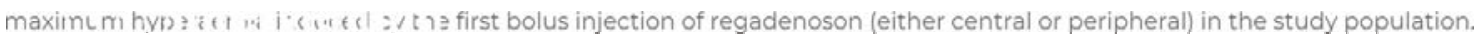

For regadenoson, following steady state hyperaemia, we observed a fluctuating level of hyperaemia with alternating levels of submaximum hyperaemia and maximum hyperaemia in 31\% of the patients (Figure 6). This state lasted for several minutes, after which hyperaemia slowly vanished without complete return of $\mathrm{Pd} / \mathrm{Pa}$ to baseline. The cycle length of this fluctuation was unpredictable and variable within one patient.
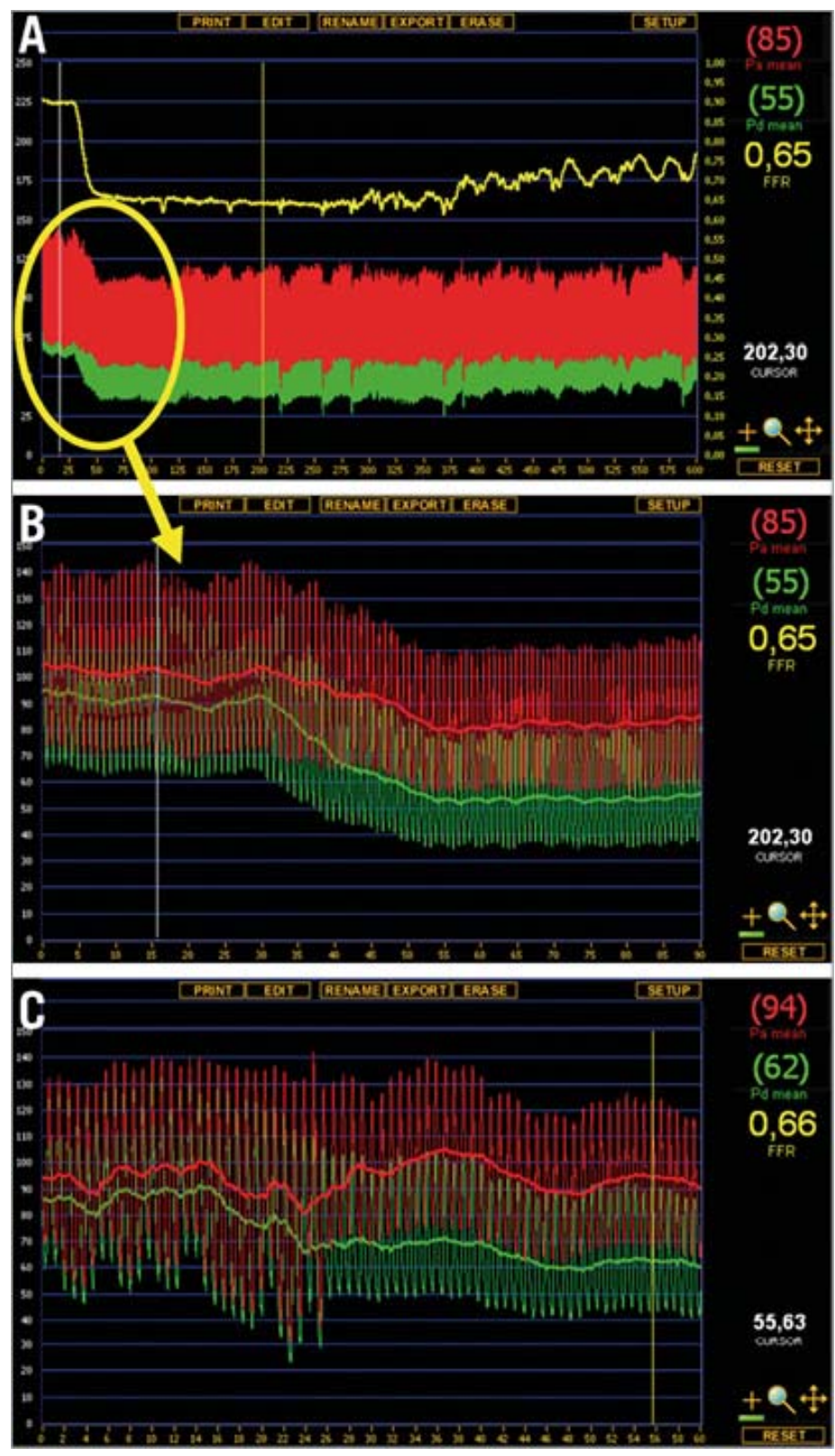

Figure 6. Maximum hyperaemia followed by fluctuating levels of hyperaemia after regadenoson injection and corresponding adenosine infusion. Example of hyperaemia induced by regadenoson and adenosine. A) Full registration of regadenoson-induced hyperaemia (peripheral single bolus injection, $400 \mu \mathrm{g}$ ). Following a steady state hyperaemia for approximately five minutes, a fluctuating state of submaximal hyperaemia occurs, before hyperaemia fades. B) Detail of the steady state hyperaemia with regadenoson injection. C)

Corresponding maximum hyperaemia with central venous infusion of adenosine in the same patient.

\section{SIDE EFFECTS AND SAFETY OF REPEATED REGADENOSON INJECTIONS}

The vast majority of all patients experienced the well-known chest discomfort or shortness of breath, both during adenosine administration as well as after regadenoson administration. The severity of chest complaints, graded on the discomfort scale described above, was classified as 6/10 for adenosine and 4/10 for regadenoson $(p<0.001)$. P t a single patient was th eason to stop the infusior lot to complete the stud tocol. 
With adenosine, this chest discomfort persisted as long as the infusion lasted, while with regadenoson the chest

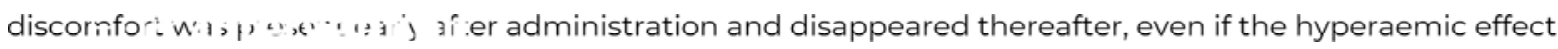
persisted.

During the 200 runs of central venous adenosine infusion in this study, no serious side effects were noted and in only six patients innocent, quickly transient, AV conduction disturbances occurred without the necessity to interrupt administration. In five cases, AV conduction disturbances occurred only with adenosine infusion, and in one case the conduction disturbance occurred with both drugs. No other side effects, except the well-known chest discomfort, were observed with intravenous adenosine. Apart from the chest discomfort and one case of AV conduction disturbances, no side effects were seen with the injections of regadenoson (either peripheral or central).

The influence of adenosine and regadenoson on blood pressure and heart rate is presented in Table 2 . Systolic and diastolic blood pressure decreased by $4 \%$ and $6 \%$, respectively, during administration of central venous adenosine, and by $6 \%$ and $7 \%$, respectively, after regadenoson injections. Heart rate increased by seven beats per minute (10\%) during adenosine administration, compared to 14 beats per minute (20\%) after regadenoson $(p<0.001)$.

Table 2. Haemodynamic effects of adenosine and regadenoson.

\begin{tabular}{|c|c|c|c|}
\hline & Baseline & Adenosine & Regadenoson \\
\hline $\mathrm{SBP}(\mathrm{mmHg})$ & $130 \pm 22$ & $126 \pm 24$ & $122 \pm 23^{*}$ \\
\hline DBP (mmHg) & $67 \pm 10$ & $63 \pm 12$ & $62 \pm 11^{\prime}$ \\
\hline HR (bpm) & $69 \pm 12$ & $76 \pm 14$ & $83 \pm 13^{\ddagger}$ \\
\hline \multicolumn{4}{|c|}{$\begin{array}{l}\text { Values are mean } \pm \text { SD. DBP: diastolic blood pressure; HR: heart rate; } \\
\text { SBP: systolic blood pressure. }{ }^{*} p<0.001 \text { compared to baseline, } p=0.01 \\
\text { compared to adenosine. }{ }^{\pi} p<0.001 \text { compared to baseline, } p=0.340 \\
\text { compared to adenosine. }{ }^{\ddagger} p<0.001 \text { compared to baseline, } p<0.001 \\
\text { compared to adenosine. }\end{array}$} \\
\hline
\end{tabular}

Finally, no side effects at all were associated with the repeated injection of regadenoson. Patients did not experience increasing chest discomfort and there was no additional effect on blood pressure or heart rate with the second bolus injection of regadenoson.

\section{Discussion}

This study shows that the hyperaemic effect induced by a single peripheral or central intravenous injection of $400 \mu \mathrm{g}$ of regadenoson is equal to hyperaemia after central venous infusion of adenosine, considered as the gold standard for inducing maximum coronary hyperaemia.

It is the largest prospective study up until now $(n=100)$ comparing the hyperaemic effect of regadenoson and adenosine and the first not only looking at maximum coronary hyperaemia, but also at duration of maximum hyperaemia, different ways of administration of regadenoson injections, and the reproducibility and safety of repeated regadenoson injections.

In the clinical practice of the catheterisation laboratory, different hyperaemic stimuli can be used. The easiest is intracoronary adenosine, which is satisfactory in non-complex coronary artery disease, but acts too briefly to perform a pressure pullback recording or to assess serial lesions. Intracoronary papaverine acts longer, but is sometimes accompanied by undesirable arrhythmias. On top of that, intracoronary administration of adenosine as well as papaverine is not reliable when assessing ostial lesions. Peripheral venous infusion of adenosine has a slower onset of action and less reliable coronary hyperaemia4. Central venous infusion of adenosine creates steady state coronary hyperaemia and is very useful in more complex coronary artery disease, particularly if a pressure pullback recording has to be made. However, as stated in the introduction, it has some practical disadvant

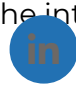


As shown in this study, hyperaemia induced by regadenoson has a rapid onset, within one minute in all cases. Although the ( $\mathrm{i}$ д almost all patients. In addition, regadenoson can be used to assess ostial lesions, has no noticeable side effects, apart from the well-known chest discomfort, and is safe for repeated administration. The price of a single vial of regadenoson, used for one single bolus injection, is roughly equivalent to that of a vial of adenosine.

Finally, if administered peripherally, the action is equal to central venous injection. This means that introduction of a central venous sheath can be avoided. This study shows that regadenoson is a suitable alternative in many patients for central venous infusion of adenosine to induce maximum coronary hyperaemia.

In recent years, several non-randomised studies have been performed to investigate the hyperaemic effects of regadenoson with comparable excellent results10-12. However, none of these studies systematically tested the reproducibility of regadenoson bolus injections and the safety of consecutive administrations, nor compared central versus peripheral administration, nor studied the time intervals of length of the hyperaemic plateau or the duration of action.

A specific observation of interest in this study was that steady state hyperaemia with regadenoson was followed by a phase of fluctuating levels of (submaximum) hyperaemia, where sometimes the minimal value of $\mathrm{Pd} / \mathrm{Pa}$ was achieved (FFR), alternating with periods of submaximum hyperaemia. These fluctuations can sometimes be observed with central venous infusion of adenosine as well, specifically if the dosage is not high enough or if the patient is performing Valsalva manoeuvres, due to suboptimal dosages of adenosine reaching the coronary circulation 15,16. This variable duration of maximum hyperaemia and subsequent fluctuating level of hyperaemia with regadenoson injection has not been described before. Probably both the variable duration of maximum hyperaemia as well as this fluctuation in the decline phase of hyperaemia are due to the metabolisation of regadenoson. Most likely this does not affect its usability in myocardial perfusion imaging, since regadenoson has already proven to be non-inferior to adenosine17.

A recent FDA warning (November 2013) drew attention to the use of regadenoson in cardiac nuclear stress testing, reporting cases of myocardial infarction and death following the stress test. In our study, we did not see any of these complications, not even with repeated administration of regadenoson. Nevertheless, it should be kept in mind that all systemic vasodilatory drugs can cause myocardial ischaemia in severe coronary artery disease due to coronary steal in a collateral-dependent myocardial distribution, irrespective of which drug is used.

Finally, in the current practice with a high prevalence of radial procedures in many catheterisation laboratories, the opportunity to administer a hyperaemic stimulus by a single peripheral injection is often advantageous because the routinely present peripheral venous access can be used without the necessity of extra punctures. Therefore, the decision for ad hoc FFR measurement during a radial procedure is facilitated.

\section{Limitations}

The hyperaemic plateau after a single bolus injection of regadenoson ranged from 10 seconds to more than 10 minutes. A ten-second window of steady state hyperaemia is too short in some patients for performing extensive pressure pullback recordings in order to be informed about the spatial distribution of disease along a coronary artery. Therefore, in patients with complex or diffuse coronary artery disease, adenosine remains the drug of choice. We cannot explain this variation in length of the hyperaemic plateau with regadenoson. Although regadenoson is administered as a non-weight-based injection, we looked at the relation between body weight and length of the hyperaemic plateau without finding a correlation $(r=0.375)$. Another possible explanation could be the use of caffeine, which is known to attenuate the duration of coronary vasodilatation induced by regadenoson at high concentrations ${ }^{18}$. To test this hypothesis, we measured caffeine levels during the procedure in 15 patients, which did not show any correlation to the duration of the hyperaemic plateau $(r=0.481)$.

Furthermore, this study proves the safety of two injections of regadenoson within a few minutes (four to 12 minutes, depending on the duration of hyperaemia after the first regadenoson injection), but did not investigate the safety of more than two injections of regadenoson. Therefore, for the time being, use of regadenoson for FFR measurement is recommended only when measurements have to be performed in one or two arteries.
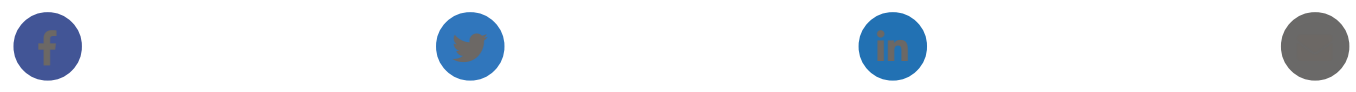
Finally, the hyperaemic effect of regadenoson was studied only in patients with stable coronary artery disease. It

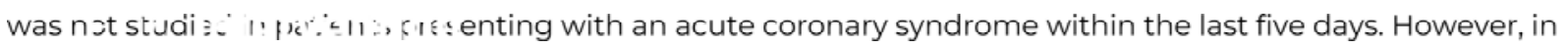
acute coronary syndrome, measurement of FFR is generally not indicated.

\section{Conclusions}

Maximum coronary hyperaemia can be achieved easily, rapidly, and reproducibly by one single body-weightindependent intravenous bolus injection of regadenoson administered in either a central or a peripheral vein. The onset of hyperaemia occurs within 30 seconds and the hyperaemic plateau is sufficiently long to perform a pressure pullback recording in almost all patients. Repeated administration of regadenoson is safe and can be necessary because the hyperaemic plateau after a single injection is quite variable. Finally, this study also confirms the safety and reliability of central venous adenosine infusion, as steady state maximum coronary hyperaemia was achieved in all patients without noticeable side effects.

\section{Impact on daily practice}

Regadenoson is an easy, rapid and safe hyperaemic stimulus creating maximum coronary hyperaemia comparable to central venous adenosine infusion for measuring FFR. It is bodyweight-independent and can be administered in a peripheral vein. Therefore, its use is practical for ad hoc FFR measurement during diagnostic angiography and in radial procedures.

\section{Funding}

This study was supported by an unrestricted educational grant from Rapidscan Pharma Solutions and by the Dutch Technology Foundation STW (Stichting voor de Technische Wetenschappen) under project number 11052.

\section{Conflict of interest statement}

N. Pijls receives research grants from St. Jude Medical and is consultant for St. Jude Medical and HeartFlow. M. van 't Veer is consultant for St. Jude Medical. P. Tonino received research grants from St. Jude Medical. The other authors have no conflicts of interest to declare.

adenosine coronary hyperaemia fractional flow reserve regadenoson

\section{References}

1. Pijls NH, De Bruyne B, Peels K, van der Voort PH, Bonnier HJ, Bartunek J, Koolen JJ. Measurement of fractional flow reserve to assess the functional severity of coronary-artery stenoses. N Engl J Med. 1996;334:1703-8.

2. Pijls NH, Sels JW. Functional measurement of coronary stenosis. J Am Coll Cardiol. 2012;59:1045-57.

3. Pijls NH, Tanaka N, Fearon WF. Functional assessment of coronary stenoses: can we live without it? Eur Heart J. 2013;34:1335-44.

4. De Bruyne B, Pijls NH, Barbato E, Bartunek J, Bech JW, Wijns W, Heyndrickx GR. Intracoronary and intravenous adenosine 5'triphosphate, adenosine, papaverine, and contrast medium to assess fractional flow reserve in humans. Circulation. 2003;107:1877-83.

5. Berry C, van 't Veer M, Witt N, Kala P, Bocek O, Pyxaras SA, McClure JD, Fearon WF, Barbato E, Tonino PA, De Bruyne B, Pijls NH, Oldroyd KG. VERIFY (VERification of Instantaneous Wave-Free Ratio and Fractional Flow Reserve for the Assessment of Coronary Artery Stenosis Severity in EverydaY Practice): a multicenter study in consecutive patients. J Am Coll Cardiol. 2013;61:1421-7.

6. Sen S, Escaned J, Malik IS, Mikhail GW, Foale RA, Mila R, Tarkin J, Petraco R, Broyd C, Jabbour R, Sethi A, Baker CS, Bellamy M, AlBustami M, Hackett D, Khan M, Lefroy D, Parker KH, Hughes AD, Francis DP, Di Mario C, Mayet J, Davies JE. Development and validation of a new adenosine-independent index of stenosis severity from coronary wave-intensity analysis: results of the ADVISE (ADenosine Vasodilator Independent Stenosis Evaluation) study. J Am Coll Cardiol. 2012;59:1392-402.

7. Jeremias A. Maehara A, Genereux P, Asrress KN Berry C, De Bruyne B, Davies JE, Escaned J, Fearon WF, Gould KL, Johnson NP, Kirtane AJ, $\quad$ K, Marques KM, Nijjer S, Oldrc J Petraco R, Piek JJ, Pijls NH, ood S, Siebes M, Spaan JA, va Jer M, Mintz 
GS, Stone GW. Multicenter core laboratory comparison of the instantaneous wave-free ratio and resting P/P with fractional flow

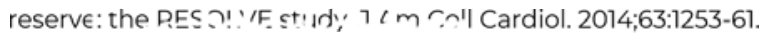

8. Johnson NP, Kirkeeide RL, Asrress KN, Fearon WF, Lockie T, Marques KM, Pyxaras SA, Rolandi MC, van 't Veer M, De Bruyne B, Piek JJ, Pijls NH, Redwood S, Siebes M, Spaan JA, Gould KL. Does the instantaneous wave-free ratio approximate the fractional flow reserve? J Am Coll Cardiol. 2013;61:1428-35.

9. Al Jaroudi W, Iskandrian AE. Regadenoson: a new myocardial stress agent. J Am Coll Cardiol. 2009;54:1123-30.

10. Arumugham P, Figueredo VM, Patel PB, Morris DL. Comparison of intravenous adenosine and intravenous regadenoson for the measurement of pressure-derived coronary fractional flow reserve. Eurolntervention. 2013;8:1166-71.

11. Nair PK, Marroquin OC, Mulukutla SR, Khandhar S, Gulati V, Schindler JT, Lee JS. Clinical utility of regadenoson for assessing fractional flow reserve. JACC Cardiovasc Interv. 2011;4:1085-92.

12. Prasad A, Zareh M, Doherty R, Gopal A, Vora H, Somma K, Mehra A, Clavijo LC, Matthews RV, Shavelle DM. Use of regadenoson for measurement of fractional flow reserve. Catheter Cardiovasc Interv. 2014;83:369-74.

13. Bech GJ, De Bruyne B, Pijls NH, de Muinck ED, Hoorntje JC, Escaned J, Stella PR, Boersma E, Bartunek J, Koolen JJ, Wijns W. Fractional flow reserve to determine the appropriateness of angioplasty in moderate coronary stenosis: a randomized trial. Circulation. 2001;103:2928-34.

14. Bland JM, Altman DG. Statistical methods for assessing agreement between two methods of clinical measurement. Lancet. 1986;1:307-10.

15. Pijls NH, Kern MJ, Yock PG, De Bruyne B. Practice and potential pitfalls of coronary pressure measurement. Catheter Cardiovasc Interv. 2000;49:1-16.

16. Wilson RF, Wyche K, Christensen BV, Zimmer S, Laxson DD. Effects of adenosine on human coronary arterial circulation. Circulation. 1990;82:1595-606.

17. Iskandrian AE, Bateman TM, Belardinelli L, Blackburn B, Cerqueira MD, Hendel RC, Lieu H, Mahmarian JJ, Olmsted A, Underwood SR, Vitola J, Wang W; ADVANCE MPI Investigators. Adenosine versus regadenoson comparative evaluation in myocardial perfusion imaging: results of the ADVANCE phase 3 multicenter international trial. J Nucl Cardiol. 2007;14:645-58.

18. Zhao G, Messina E, Xu X, Ochoa M, Sun HL, Leung K, Shryock J, Belardinelli L, Hintze TH. Caffeine attenuates the duration of coronary vasodilation and changes in hemodynamics induced by regadenoson (CVT-3146), a novel adenosine A2A receptor agonist. J Cardiovasc Pharmacol. 2007;49:369-75. 